\title{
The risk of new fragility fractures in patients with chronic kidney disease and hip fracture-a population-based cohort study in the UK
}

\author{
I.J.A. de Bruin ${ }^{1,2}$ (D) C C.E. Wyers ${ }^{1,2}$ (D) P.C. Souverein ${ }^{3}$ (D) T.P. van Staa ${ }^{3,4}$ (D) \\ P.P.M.M. Geusens ${ }^{5,6}$ (D) J.P.W. van den Bergh ${ }^{1,2,5}$ (D) F. de Vries $^{3,7,8}$ (D) \\ J.H.M. Driessen ${ }^{3,7,8,9}$
}

Received: 15 November 2019 / Accepted: 14 February 2020 / Published online: 7 April 2020

(C) The Author(s) 2020

\begin{abstract}
Summary Chronic kidney disease (CKD) is a risk factor for fractures. However, in hip fracture patients, CKD G3-G5 was associated with a higher mortality risk and not associated with a higher risk of subsequent non-hip fractures compared to eGFR > $60 \mathrm{ml} / \mathrm{min}$. The higher mortality risk may, as competing risk, explain our findings.

Introduction Chronic kidney disease (CKD) is a known risk factor for fragility fractures. Patients aged 50+ with a recent fragility fracture have an increased risk of subsequent fractures. Our aim was to evaluate the association between CKD stages G3-G5 versus estimated glomerular filtration rate (eGFR) $>60 \mathrm{ml} / \mathrm{min}$ and the risk of a new non-hip fracture or fragility fracture in patients with a first hip fracture.

Methods Population-based cohort study using the UK general practices in the Clinical Practice Research Datalink. Associations between CKD stage and first subsequent fracture were determined using Cox proportional hazard analyses to estimate hazard ratios (HRs). To explore the potential competing risk of mortality, cause-specific (cs) HRs for mortality were estimated.

Results CKD G3-G5 was associated with a lower risk of any subsequent non-hip fracture (HR: 0.90, 95\%CI: 0.83-0.97), but not with the risk of subsequent major non-hip fragility fracture. CKD G3-G5 was associated with a higher mortality risk (cs-HR: 1.05, 95\%CI: 1.01-1.09). Mortality risk was 1.5- to 3-fold higher in patients with CKD G4 (cs-HR: 1.50, 95\%CI: 1.38-1.62) and G5 (cs-HR: 2.93, 95\%CI: 2.48-3.46) compared to eGFR > $60 \mathrm{ml} / \mathrm{min}$.

Conclusions The risk of a subsequent major non-hip fragility fractures following hip fracture was not increased in patients with CKD G3-G5 compared to eGFR > $60 \mathrm{ml} / \mathrm{min}$. Mortality risk was higher in both hip fracture and non-hip fracture patients with CKD G4 and G5. The higher mortality risk may, as competing risk, explain our main finding of no increased or even decreased subsequent fracture risk after a hip fracture in patients with CKD G3-G5.
\end{abstract}

Electronic supplementary material The online version of this article (https://doi.org/10.1007/s00198-020-05351-x) contains supplementary material, which is available to authorized users.

F. de Vries

f.devries@uu.nl

1 Department of Internal Medicine, VieCuri Medical Center, Venlo, The Netherlands

2 NUTRIM School for Nutrition and Translational Research in Metabolism, Department of Internal Medicine, Maastricht University Medical Centre+, Maastricht, The Netherlands

3 Division of Pharmacoepidemiology and Clinical Pharmacology, Utrecht Institute of Pharmaceutical Sciences, P.O. Box 80082, 3508 TB Utrecht, The Netherlands

4 Centre for Health Informatics, School of Health Sciences, Faculty of Biology, Medicine and Health, The University of Manchester, Oxford Road, Manchester, England
5 Biomedical Research Center, Hasselt University, Diepenbeek, Belgium

6 CAPHRI Care and Public Health Research Institute, Department of Internal Medicine, Subdivision Rheumatology, Maastricht University Medical Centre+, Maastricht, The Netherlands

7 Department of Clinical Pharmacy and Toxicology, Maastricht University Medical Centre+, Maastricht, The Netherlands

8 Cardiovascular Research Institute Maastricht, Maastricht University Medical Centre+, Maastricht, The Netherlands

$9 \quad$ NUTRIM School for Nutrition and Translational Research in Metabolism, Maastricht University, Maastricht, The Netherland 
Keywords Bone $\cdot$ Chronic renal failure $\cdot$ Fragility fracture $\cdot$ Renal disease

\section{Introduction}

Chronic kidney disease (CKD) is a known risk factor for fragility fractures, in particular the first fragility fracture [1-6]. Previous research has shown that CKD (an estimated glomerular filtration rate (eGFR) of $<60 \mathrm{ml} / \mathrm{min}$ ) is associated with an increased prevalence of hip fractures [2]. This was confirmed by a crosssectional study among German elderly $(n=5313)$ which showed that an eGFR $<65 \mathrm{ml} / \mathrm{min}$ was associated with increased risk of fractures of the femur, vertebrae and radius [3]. It was shown that CKD G3a and G3b were associated with an increased risk of any type of fracture as compared to CKD G1-G2 in both men and women [6]. In men with CKD stage G4, the risk of hip fracture was found to be increased compared with men with a normal renal function [5]. Further, in patients with end-stage renal disease, it was reported that both women and men had a relative risk of 4.4 for sustaining a hip fracture as compared with people of the same sex in the general population [4].

Patients aged 50 years and older who recently sustained a fragility fracture are at increased risk of subsequent fractures [7-10]. This subsequent fracture risk is the highest following hip fractures and clinical vertebral fractures [8]. An excess fracture-related mortality risk in patients aged $60-80$ years with a minimal trauma fracture was demonstrated by Bliuc et al. [11], with the highest post-fracture mortality after a hip fracture $[11,12]$.

So far, published studies have investigated the association between CKD and the risk of a first fragility fracture. However, the association between CKD and subsequent fracture risk is unknown. Therefore, the objectives of this study were to evaluate the association between CKD (stages G3-G5 versus eGFR > $60 \mathrm{ml} / \mathrm{min}$ ) and the risk of a subsequent major non-hip fragility fracture (humerus, distal forearm and vertebral fracture) or any non-hip subsequent fracture in patients with a first hip fracture.

\section{Materials and methods}

\section{Source population}

Data for this study were obtained from the Clinical Practice Research Datalink (CPRD) GOLD in the United Kingdom (UK), previously known as the General Practice Research Database (GPRD) [www.CPRD.com]. The CPRD GOLD contains computerised medical records of 674 primary care practices in the UK, representing $6.9 \%$ of the UK population. The data recorded in the CPRD include demographic information, prescription details, clinical events, preventive care provided, specialist referrals, hospital admissions, and major outcomes since 1987, with ongoing data collection [13]. Previous studies using CPRD data have shown to be highly valid, with for example for hip fractures over 90\% confirmed diagnoses [14]. CPRD GOLD had a high quality of recording of all-cause mortality [15].

\section{Study population}

We conducted a retrospective population-based cohort study. The study population consisted of all patients aged $\geq 50$ at start of follow-up with a first hip fracture during the period of valid CPRD data collection. For this study, data collection started in April 2004 (i.e. when the Quality and Outcomes Framework (QOF) was introduced) and ended in December 2016. Patients with a hip fracture were matched by sex, year of birth (maximum difference of 5 years) and practice to up to two control patients without a hip fracture using incidence density sampling. The index date was set to the date of the first record of a hip fracture. The index date of controls was set to the index date of their matched hip fracture patient. There was a lead-in period of 1 month after the hip fracture date in order to avoid any delayed recording of fractures that occurred at the index date. Patients with records of unspecified fracture types before the index date were excluded. Patients were followed from the index date until the end of data collection, date of transfer of the patient out of the practice, the patient's death or outcome of interest, whichever came first. Patients with a history of a kidney transplantation before the index date were excluded.

\section{Exposure and outcome}

The eGFR was assessed in a time-dependent manner. Follow-up time in both cohorts was divided into 90-day intervals. For all patients, the most recently recorded renal function assessed in the time period ranging from 1 week to 1 year before the start of an interval was evaluated. Renal function was estimated by using the recorded laboratory test data. The reported eGFR or, if only a serum creatinine measurement was available, the Modification of Diet in Renal Disease (MDRD) formula was used to calculate eGFR values, according to the methods by Eppenga et al. [16]. In the event of multiple eGFR values on the same day, the mean value was used. The "Kidney Disease: Improving Global Outcomes" (KDIGO) classification for CKD consists of five stages: G1: eGFR $>90 \mathrm{ml} / \mathrm{min} / 1.73 \mathrm{~m}^{2}$, G2: eGFR $60-89 \mathrm{ml} /$ $\mathrm{min} / 1.73 \mathrm{~m}^{2}$, G3: eGFR 30-59 ml/min/1.73 m², G4: eGFR 15$29 \mathrm{ml} / \mathrm{min} / 1.73 \mathrm{~m}^{2}$ and G5: eGFR < $15 \mathrm{ml} / \mathrm{min} / 1.73 \mathrm{~m}^{2}$ [17]. Follow-up time was stratified into three levels: eGFR $\geq 60 \mathrm{ml} /$ min and eGFR $<60 \mathrm{ml} / \mathrm{min}$ (stages G3, G4 and G5 CKD) according to KDIGO, and an unknown eGFR value. We did not 
use Read codes from the clinical and referral files, which contain numerical CKD categories, since there is evidence of miscoding of the CKD codes compared with biochemically confirmed CKD [18]. As a result of this classification, patients' exposure time could move between different CKD groups during followup. We studied the following outcomes: the first subsequent major non-hip fragility fracture, the first subsequent non-hip fracture (including non-fragility fractures) and all-cause mortality. Fractures were classified using Read codes.

\section{Potential confounders}

The presence of risk factors for fracture and subsequent fracture was assessed by reviewing computerised medical records for any record of a risk factor prior to the start of an interval. The following potential confounders were considered at baseline: sex, smoking status (non-smoker, current smoker, former smoker or unknown), alcohol use (yes, no, unknown) and body mass index (BMI) $\left(<25.0,25.0-29.9, \geq 30 \mathrm{~kg} / \mathrm{m}^{2}\right.$ or unknown). Additionally, the use of any of the following drugs in the 6 months before the start of an interval was considered as a potential confounder: corticosteroids (systemic and inhaled), benzodiazepines, other sedatives and hypnotics, antiParkinson drugs, antipsychotics, antidepressants, narcotic analgesics stronger than tramadol, anticonvulsants, diuretics, renin-angiotensin-aldosterone-system (RAAS) inhibitors and drugs used for the treatment of diabetes. Also, antiosteoporosis treatments were considered as potential confounders: bisphosphonates, denosumab, strontium ranelate, calcitonin and parathyroid hormone (PTH), hormone replacement therapy (HRT), and selective estrogen receptor modulators (SERMs) and finally, vitamin D and calcium.

Other potential confounders were determined at the start of each new time interval: age, a history of a major (non-hip) fracture, inflammatory bowel disease (Crohn's disease and ulcerative colitis), rheumatoid arthritis, a history of falls (in the 7-12 months before the start of an interval) and the presence of secondary osteoporosis in accordance with the fracture risk assessment tool (FRAX) definition [anorexia nervosa, coeliac disease, type 1 diabetes mellitus, hypogonadism, osteogenesis imperfecta, osteomalacia, liver disease (cirrhosis, hepatitis and neoplasms), malnutrition, mal-absorption and premature menopause].

\section{Statistical analysis}

Cox regression analysis (SAS 9.4. PHREG procedure) was used for the primary comparison to estimate the association of normal versus reduced renal function (eGFR $<60$ vs. eGFR $\geq 60$ ) and the risk of a subsequent non-hip major osteoporotic fracture and the risk of any (non-hip) fracture after a hip fracture, expressed as hazard ratios (HRs) with $95 \%$ confidence intervals (95\% CI). Analyses were stratified by sex, age and CKD stages. CKD stage
5 was further stratified by history of dialysis. Confounders were entered into the final model if they independently changed the beta coefficient of the association between renal function and subsequent fracture by at least $5 \%$ and/or when consensus about inclusion existed within the team of researchers, supported by clinical evidence from literature. The Wald test was used to test the statistical differences between the CKD groups.

Since we performed time-dependent analyses, we were not able to perform the Fine and Gray adjustments to study mortality as potential competing risk [19]. Therefore, we estimated the cause-specific (cs)-HRs for mortality (i.e. follow-up time was not only censored on end of valid data collection, but also on the occurrence of any or major osteoporotic fracture). Further, the cumulative incidence of different outcomes (subsequent fracture and alive, subsequent fracture and death, death, alive and no subsequent fracture) after the initial hip fracture was calculated based on the paper by Bliuc et al. [20]. Missing data were handled as a separate category in the regression models.

\section{Sensitivity analyses}

In a sensitivity analysis, we studied the association between renal function and the risk of a first major non-hip osteoporotic fracture (humerus, distal forearm and vertebral fracture) and any non-hip fracture in the control cohort (non-hip fracture cohort). We also studied the risk of mortality in the non-hip fracture cohort. The cumulative incidence of different outcomes (major osteoporotic fracture (MOF) and alive, MOF and death, death, alive and no MOF) was calculated in the non-hip fracture cohort as well. Further, we preformed two additional sensitivity analyses in high-risk patients. We selected patients who had a history of falling or a history of a fragility fracture at baseline and investigated the association between kidney function and risk of fracture in those two study populations. Moreover, we estimated the risk of fracture and all-cause mortality in the first year and second year after the index date in both the hip fracture population and in the nonhip fracture cohort. The study was approved by the Independent Scientific Advisory Committee for MHRA database research, protocol 17_260R2.

\section{Results}

The hip fracture cohort consisted of 37,820 patients. At baseline, the CKD classification of 23,780 patients was known: $13,047 \mathrm{had}$ an eGFR $>60 \mathrm{ml} / \mathrm{min}$ and $10,733 \mathrm{had}$ CKD stages G3-G5. The control population comprised 74,440 patients in total. The reasons for exclusion are shown in the flowcharts of the hip fracture cohort and matched controls (Supplemental Fig. 1). Baseline characteristics of both the hip fracture cohort and the control cohort are shown in Table 1. In the group of 
Table 1 Baseline characteristics

\begin{tabular}{|c|c|c|c|c|c|c|c|c|}
\hline \multirow[b]{3}{*}{ Characteristic } & \multicolumn{4}{|c|}{ Patients with a hip fracture } & \multicolumn{4}{|c|}{ Patients without a hip fracture } \\
\hline & \multicolumn{2}{|c|}{$\mathrm{eGFR}>60 \mathrm{ml} / \mathrm{min}$} & \multicolumn{2}{|c|}{ CKD stages G3-G5 } & \multicolumn{2}{|c|}{$\mathrm{eGFR}>60 \mathrm{ml} / \mathrm{min}$} & \multicolumn{2}{|c|}{ CKD stages G3-G5 } \\
\hline & $N=13,047$ & $\%$ & $N=10,733$ & $\%$ & $N=25,072$ & $\%$ & $N=19,511$ & $\%$ \\
\hline Mean Follow-up time (SD) (years) & 3.2 & 2.9 & 2.8 & 2.8 & 4.3 & 3.1 & 4.1 & 3.1 \\
\hline Median Follow-up time (IQR) (years) & 2.4 & 4.2 & 1.8 & 3.8 & 3.7 & 4.6 & 3.3 & 4.6 \\
\hline \multicolumn{9}{|l|}{ Sex } \\
\hline Men & 3945 & 30.2 & 2540 & 23.7 & 7697 & 30.7 & 4193 & 21.5 \\
\hline Women & 9102 & 69.8 & 8193 & 76.3 & 17,375 & 69.3 & 15,318 & 78.5 \\
\hline \multicolumn{9}{|l|}{ Age } \\
\hline Mean age (SD, years) & 79.2 & 9.7 & 84.2 & 7.5 & 79.0 & 9.5 & 84.1 & 6.9 \\
\hline $50-59$ years & 588 & 4.5 & 64 & 0.6 & 1056 & 4.2 & 80 & 0.4 \\
\hline $60-69$ years & 1609 & 12.3 & 387 & 3.6 & 3070 & 12.2 & 581 & 3.0 \\
\hline 70-79 years & 3610 & 27.7 & 2033 & 18.9 & 7265 & 29.0 & 3696 & 18.9 \\
\hline $80-89$ years & 5571 & 42.7 & 5648 & 52.6 & 10,922 & 43.6 & 10,804 & 55.4 \\
\hline $90+$ years & 1669 & 12.8 & 2601 & 24.2 & 2759 & 11.0 & 4350 & 22.3 \\
\hline \multicolumn{9}{|l|}{ Body mass index } \\
\hline Mean $\left(\mathrm{SD}, \mathrm{kg} / \mathrm{m}^{2}\right)$ & 25.3 & 4.6 & 26.1 & 4.7 & 26.39 & 4.7 & 26.86 & 4.7 \\
\hline$<18 \mathrm{~kg} / \mathrm{m}^{2}$ & 406 & 3.1 & 186 & 1.7 & 300 & 1.2 & 187 & 1.0 \\
\hline $18-24.9 \mathrm{~kg} / \mathrm{m}^{2}$ & 5725 & 43.9 & 4068 & 37.9 & 9513 & 37.9 & 6462 & 33.1 \\
\hline $25-29.9 \mathrm{~kg} / \mathrm{m}^{2}$ & 4113 & 31.5 & 3657 & 34.1 & 9422 & 37.6 & 7435 & 38.1 \\
\hline $30-34.9 \mathrm{~kg} / \mathrm{m}^{2}$ & 1291 & 9.9 & 1264 & 11.8 & 3329 & 13.3 & 2930 & 15.0 \\
\hline$\geq 35 \mathrm{~kg} / \mathrm{m}^{2}$ & 356 & 2.7 & 408 & 3.8 & 1112 & 4.4 & 1004 & 5.1 \\
\hline Missing & 1156 & 8.9 & 1150 & 10.7 & 1396 & 5.6 & 1493 & 7.7 \\
\hline \multicolumn{9}{|l|}{ Smoking status } \\
\hline Non-smoker & 4490 & 34.4 & 3970 & 37.0 & 9316 & 37.2 & 7492 & 38.4 \\
\hline Ex-smoker & 6412 & 49.1 & 5637 & 52.5 & 13,457 & 53.7 & 10,701 & 54.8 \\
\hline Current smoker & 2042 & 15.7 & 1009 & 9.4 & 2201 & 8.8 & 1218 & 6.2 \\
\hline Missing & 103 & 0.8 & 117 & 1.1 & 98 & 0.4 & 100 & 0.5 \\
\hline \multicolumn{9}{|l|}{ Alcohol use } \\
\hline Yes & 7513 & 57.6 & 5568 & 51.9 & 16,141 & 64.4 & 11,049 & 56.6 \\
\hline No & 4362 & 33.4 & 4057 & 37.8 & 7415 & 29.6 & 6984 & 35.8 \\
\hline Missing & 1172 & 9.0 & 1108 & 10.3 & 1516 & 6.0 & 1478 & 7.6 \\
\hline \multicolumn{9}{|l|}{ Disease history } \\
\hline Fragility fracture $^{a}$ & 2588 & 19.8 & 2195 & 20.5 & 2900 & 11.6 & 2580 & 13.2 \\
\hline Falling (7-12 months prior index date) & 783 & 6.0 & 685 & 6.4 & 773 & 3.1 & 729 & 3.7 \\
\hline Secondary osteoporosis ${ }^{\mathrm{b}}$ & 785 & 6.0 & 643 & 6.0 & 957 & 3.8 & 806 & 4.1 \\
\hline Inflammatory bowel disease ${ }^{c}$ & 212 & 1.6 & 168 & 1.6 & 286 & 1.1 & 228 & 1.2 \\
\hline Rheumatoid arthritis & 631 & 4.8 & 429 & 4.0 & 798 & 3.2 & 526 & 2.7 \\
\hline Cancer (excluding nonmelanoma skin cancers) & 4293 & 32.9 & 3322 & 31.0 & 8123 & 32.4 & 5946 & 30.5 \\
\hline Diabetes mellitus type 2 & 2138 & 16.4 & 2186 & 20.4 & 4236 & 16.9 & 3834 & 19.7 \\
\hline \multicolumn{9}{|l|}{ Drugs history (in 6 months prior to index date) } \\
\hline Antipsychotics & 850 & 6.5 & 645 & 6.0 & 599 & 2.4 & 588 & 3.0 \\
\hline Antidepressants & 3903 & 29.9 & 3075 & 28.6 & 4471 & 17.8 & 3681 & 18.9 \\
\hline Anticonvulsants & 1015 & 7.8 & 589 & 5.5 & 992 & 4.0 & 722 & 3.7 \\
\hline Anti-Parkinson drugs & 431 & 3.3 & 264 & 2.5 & 310 & 1.2 & 205 & 1.1 \\
\hline Corticosteroids (systemic and inhaled) & 2950 & 22.6 & 2197 & 20.5 & 4564 & 18.2 & 3467 & 17.8 \\
\hline Benzodiazepines and other sedatives & 2377 & 18.2 & 1954 & 18.2 & 2661 & 10.6 & 2567 & 13.2 \\
\hline Narcotic analgesics stronger than tramadol & 1109 & 8.5 & 900 & 8.4 & 1023 & 4.1 & 989 & 5.1 \\
\hline
\end{tabular}


Table 1 (continued)

\begin{tabular}{|c|c|c|c|c|c|c|c|c|}
\hline \multirow[b]{3}{*}{ Characteristic } & \multicolumn{4}{|c|}{ Patients with a hip fracture } & \multicolumn{4}{|c|}{ Patients without a hip fracture } \\
\hline & \multicolumn{2}{|c|}{$\mathrm{eGFR}>60 \mathrm{ml} / \mathrm{min}$} & \multicolumn{2}{|c|}{ CKD stages G3-G5 } & \multicolumn{2}{|c|}{$\mathrm{eGFR}>60 \mathrm{ml} / \mathrm{min}$} & \multicolumn{2}{|c|}{ CKD stages G3-G5 } \\
\hline & $N=13,047$ & $\%$ & $N=10,733$ & $\%$ & $N=25,072$ & $\%$ & $N=19,511$ & $\%$ \\
\hline Bisphosphonates & 1690 & 13.0 & 1304 & 12.1 & 2511 & 10.0 & 2002 & 10.3 \\
\hline Anti-osteoporosis treatment ${ }^{\mathrm{d}}$ & 1756 & 13.5 & 1349 & 12.6 & 2588 & 10.3 & 2068 & 10.6 \\
\hline Denosumab & 3 & 0.0 & 4 & 0.00 & 11 & 0.0 & 4 & 0 \\
\hline $\mathrm{HRT}^{\mathrm{e}}$ and SERMs & 101 & 0.8 & 42 & 0.4 & 260 & 1.0 & 117 & 0.6 \\
\hline Vitamin D (cholecalciferol and ergocalciferol) & 2545 & 19.5 & 1933 & 18.0 & 3641 & 14.5 & 3225 & 16.5 \\
\hline Dihydrotachysterol & 0 & 0 & 0 & 0 & 0 & 0 & 0 & 0 \\
\hline Alfacalcidol and calcitriol & 17 & 0.1 & 164 & 1.5 & 25 & 0.1 & 212 & 1.1 \\
\hline Calcium & 119 & 0.9 & 114 & 1.1 & 162 & 0.6 & 170 & 0.9 \\
\hline Loop diuretics & 2502 & 19.2 & 3970 & 37.0 & 3803 & 15.2 & 6263 & 32.1 \\
\hline Thiazide diuretics & 2234 & 17.1 & 2245 & 20.9 & 5997 & 23.9 & 5347 & 27.4 \\
\hline RAAS inhibitors & 4631 & 35.5 & 5092 & 47.4 & 10,324 & 41.2 & 10,672 & 54.7 \\
\hline Insulin & 1624 & 12.4 & 1675 & 15.6 & 3014 & 12.0 & 2699 & 13.8 \\
\hline Metformin & 1134 & 8.7 & 869 & 8.1 & 2350 & 9.4 & 1586 & 8.1 \\
\hline Sulfonylurea & 664 & 5.1 & 761 & 7.1 & 1186 & 4.7 & 1309 & 6.7 \\
\hline Thiazolidinedione & 159 & 1.2 & 171 & 1.6 & 237 & 0.9 & 240 & 1.2 \\
\hline Dipeptyl peptidase-4 inhibitor & 74 & 0.6 & 105 & 1.0 & 213 & 0.8 & 173 & 0.9 \\
\hline Other non-insulin anti-diabetic drugs & 29 & 0.2 & 34 & 0.3 & 71 & 0.3 & 40 & 0.2 \\
\hline
\end{tabular}

$C K D$ chronic kidney disease, IQR interquartile range, $S D$ standard deviation, $H R T$ hormone replacement therapy, SERM selective oestrogen-receptor modulator, $R A A S$ renin-angiotensin- aldosterone system

The "Kidney Disease: Improving Global Outcomes" (KDIGO) classification for CKD consists of five stages: G1: eGFR >90 m1/min/1.73 m², G2:

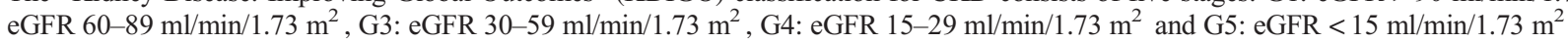

${ }^{\text {a }}$ Fragility fracture: humerus, distal fore-arm and clinical vertebrae

${ }^{\mathrm{b}}$ As defined by FRAX (anorexia nervosa, celiac disease, diabetes mellitus type 1, hypogonadism, osteogenesis imperfecta, osteomalacia, liver disease (cirrhosis, hepatitis and neoplasms), malnutrition, malabsorption and premature menopause)

${ }^{\mathrm{c}}$ Crohn's disease and ulcerative colitis

${ }^{\mathrm{d}}$ Bisphosphonates, strontium ranelate, calcitonin, PTH, denosumab

${ }^{\mathrm{e}}$ Includes oestrogen treatment

Patients with no recorded eGFR in the year before the index date are not shown in this table. $N=14,040$ for the hip fracture cohort and $N=29,857$ for the control cohort

eGFR $>60 \mathrm{ml} / \mathrm{min}$, the mean age was 79.2 years $(\mathrm{SD}=9.7)$ and $69.8 \%$ was women. In the group of CKD stages G3-G5, the mean age was 84.2 years $(\mathrm{SD}=7.5)$ and $76.3 \%$ was women. Mean BMI was higher in the CKD stages G3-G5 patients: $26.1 \mathrm{~kg} / \mathrm{m}^{2}$ in CKD stages G3-G5 vs. $25.3 \mathrm{~kg} / \mathrm{m}^{2}$ in eGFR > $60 \mathrm{ml} / \mathrm{min}$. The median follow-up time (from hip fracture until the end of data collection) was 2.4 years (IQR 4.2) in eGFR > $60 \mathrm{ml} / \mathrm{min}$ and 1.8 years (IQR 3.8) in CKD stages G3-G5.

\section{Incidence rates and risk of a subsequent major non-hip fragility fracture after initial hip fracture}

The incidence rates (IRs) for a subsequent major non-hip fragility fracture after an initial hip fracture in the group of eGFR $>60 \mathrm{ml} / \mathrm{min}$ and CKD stages G3-G5 were 20.0 per 1000 person years and 19.1 per 1000 person years, respectively.
The adjusted HR of subsequent major non-hip fragility fracture in the CKD stages G3-G5 group was not statistically significantly different from the eGFR $>60 \mathrm{ml} / \mathrm{min}$ group (adjusted HR $0.89 ; 95 \%$ confidence interval 0.79 to 1.00 ). Stratification for CKD stages showed for CKD stage G3 an adjusted HR of 0.89 (0.79 to 1.01), for CKD stage G4 0.88 (0.64 to 1.20) and for CKD stage G5 0.56 (0.20 to 1.56). Stratification by age did not show a significant difference in patients aged $<80$ years compared to $80+$ (Table 2 ).

\section{Incidence rates and risk of any subsequent non-hip fracture after initial hip fracture}

The IRs for any subsequent non-hip fracture after hip fracture were 52.1 per 1000 person years in eGFR $>60 \mathrm{ml} / \mathrm{min}$ and 48.1 per 1000 person years in CKD stages G3-G5 (Table 3). 


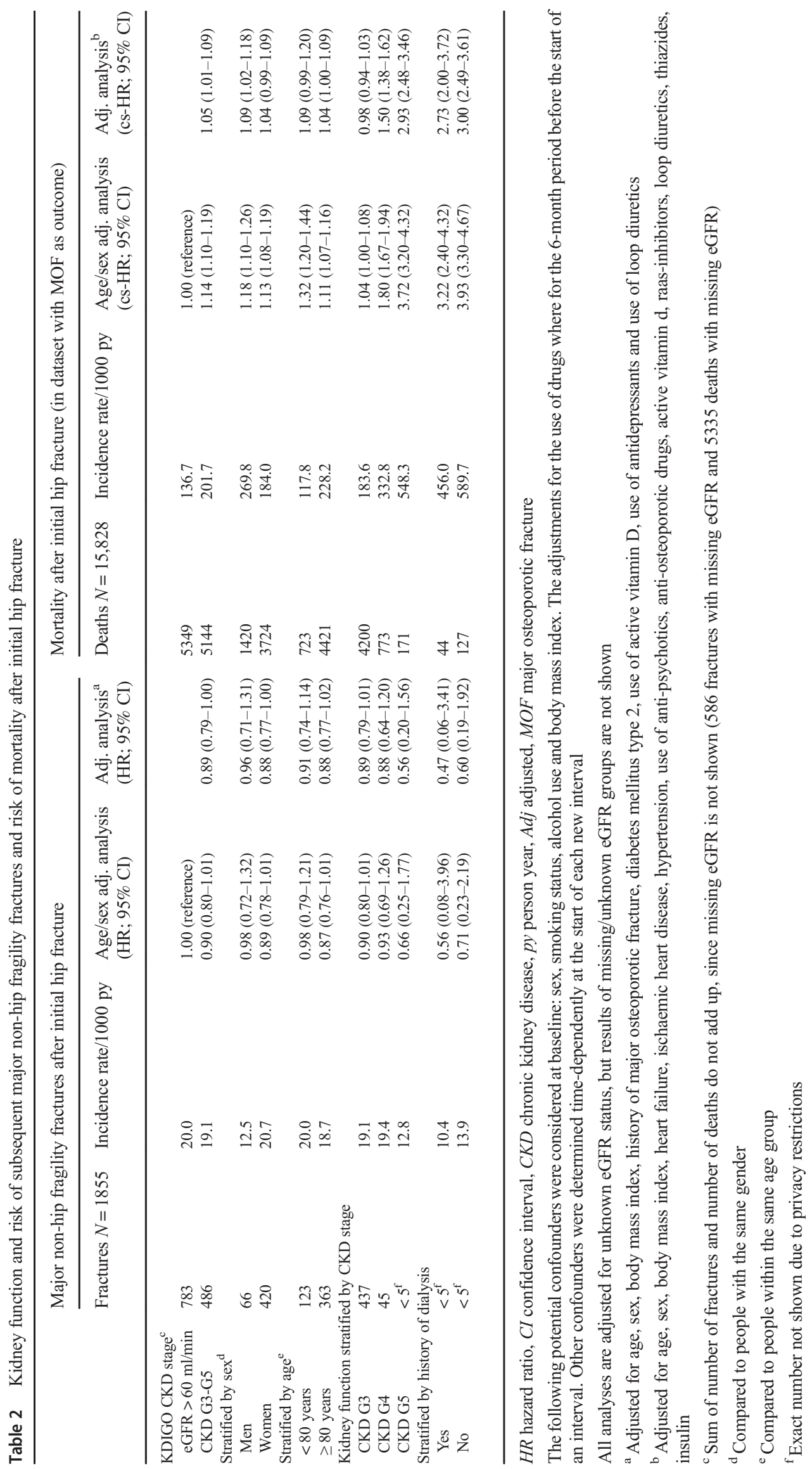




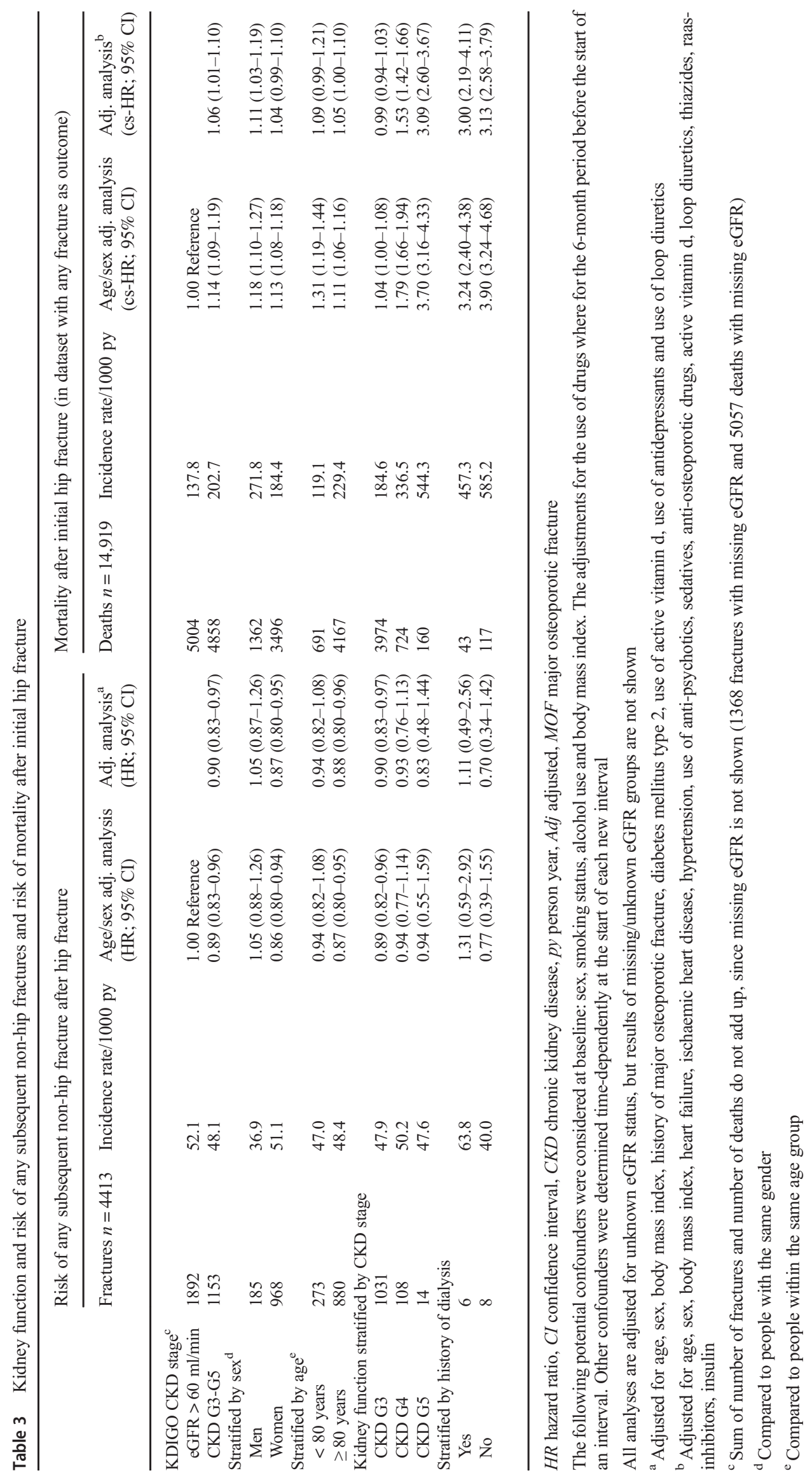


Compared to eGFR > $60 \mathrm{ml} / \mathrm{min}, \mathrm{CKD}$ stage $\mathrm{G} 3$ was associated with a lower risk of any subsequent non-hip fracture (adjusted HR 0.90 (0.83 to 0.97)). The risk of subsequent fractures in CKD stage G4 and G5 was not significantly different in comparison to eGFR $>60 \mathrm{ml} / \mathrm{min}$. Stratification by sex demonstrated a lower risk in women, adjusted HR 0.87 (0.80 to 0.95$)$.

\section{Mortality}

The IR for mortality after initial hip fracture was 136.7 per 1000 person years in eGFR $>60 \mathrm{ml} / \mathrm{min}$ and 201.7 for CKD stages G3-G5. In CKD stage G5, the IR was 548.3. The cs-HRs for mortality are shown in Table 2 . Mortality risk was significantly higher in CKD stages G3-G5 compared to eGFR > $60 \mathrm{ml} / \mathrm{min}$ (cs-HR 1.05 (1.01 to 1.09)). Stratification by CKD stage resulted in a 1.5 higher mortality risk for CKD stage G4 (cs-HR 1.50 (1.38 to 1.62)) and a 3-fold higher mortality for CKD stage G5 (cs-HR 2.93 (2.48 to 3.46)). Figure 1 shows the cumulative incidence of the different outcomes (subsequent fracture and alive, subsequent fracture and death, death, alive and no subsequent fracture) for the different CKD stages.

\section{Sensitivity analyses}

In the non-hip fracture cohort (control cohort), the IRs of first major non-hip fragility fracture were 9.9 per 1000 person years in eGFR > $60 \mathrm{ml} / \mathrm{min}$ and 11.7 in CKD stages G3-G5 (Supplemental Table 1). The IRs in the non-hip fracture group were lower than in the study group after first hip fracture. The risk of major non-hip fragility fracture and the risk of any nonhip fracture in the non-hip fracture group did not differ significantly between CKD stages G3-G5 and eGFR > $60 \mathrm{ml} / \mathrm{min}$ (Tables 1 and 2, supplemental tables). Patients with CKD stage G3 had a lower risk of any non-hip fracture compared to eGFR > $60 \mathrm{ml} / \mathrm{min}$ (HR $0.93 ; 0.87$ to 0.99 ). In the non-hip fracture group, also higher IRs of mortality in CKD stages G3-G5 were found. Mortality risk was significantly higher in CKD stages G3-G5 compared to eGFR > $60 \mathrm{ml} / \mathrm{min}$ (csHR 1.08 (1.05 to 1.12). Stratification by CKD stage resulted in an increased mortality risk in CKD stage G4 and CKD G5 (Supplemental Tables 1 and 2). In the control cohort, the cumulative incidence of the different outcomes (MOF and alive, MOF and death, death, alive and no MOF) in the CKD stages were calculated (Supplemental Fig. 2).

The sensitivity analyses in the high-risk subjects with a history of falling or a history of a fragility fracture showed similar results for the risk of subsequent major fragility fracture and mortality as in the hip fracture population. Further, CKD stages G3-G5 were not associated with subsequent fracture risk if the analysis was restricted to the first and the second year after index date. The mortality risk in the first year was higher in the CKD stages G3-G5 group compared to eGFR $>60 \mathrm{ml} / \mathrm{min}$ (cs-HR 1.16, 1.09 to 1.23 ). Stratification for CKD demonstrated an increasing mortality risk in CKD stages G3, G4 and G5. In the second year, the mortality risk was not increased in CKD stages G3-G5 compared to eGFR $>60 \mathrm{ml} / \mathrm{min}$ (cs-HR 0.99, 0.90 to 1.10 ). However, stratification for CKD showed an increased mortality risk in CKD stage G4 and CKD stage G5 (CKD stage G4 cs-HR 1.43,
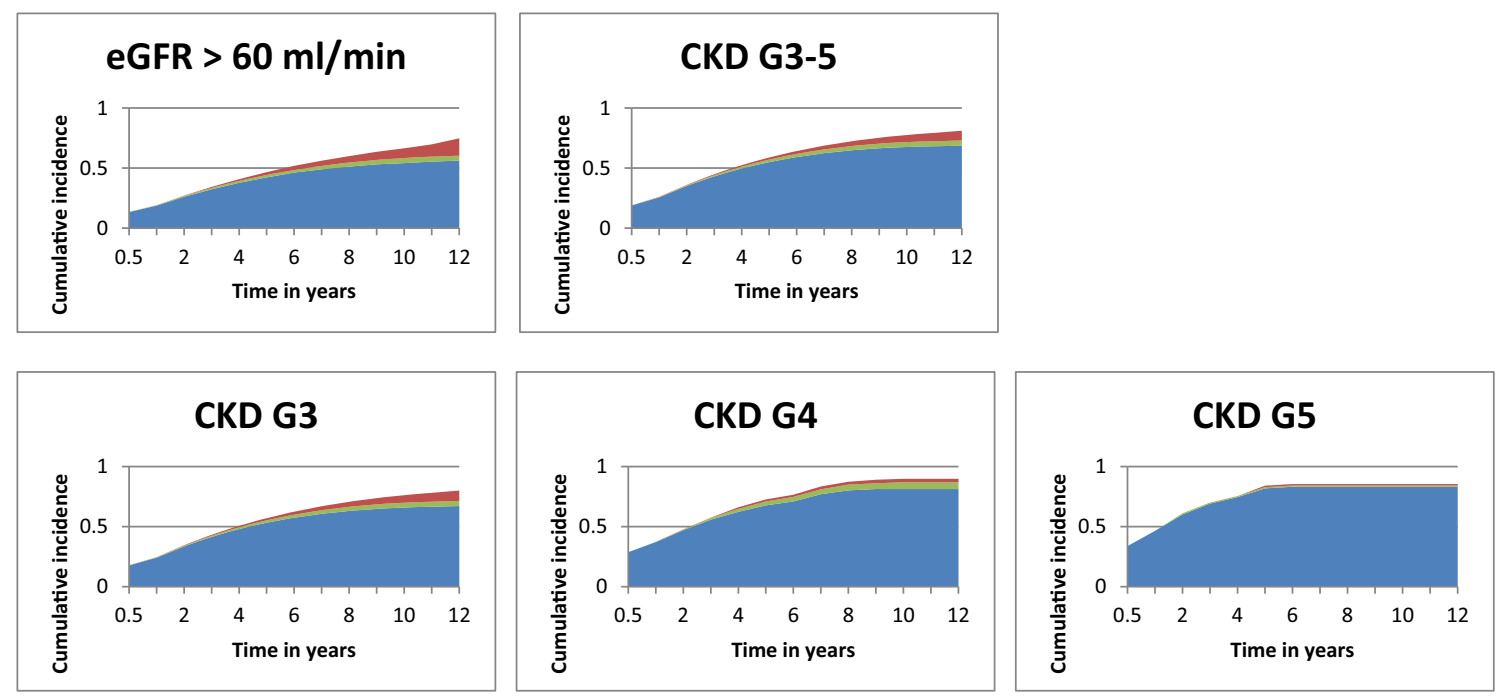

\footnotetext{
I Subsequent fracture and alive

= Subsequent fracture and death

= Death
}

Fig. 1 Cumulative incidence of different outcomes after the initial hip fracture by kidney function. Subsequent fracture is a subsequent major osteoporotic fracture 
1.16 to 1.76 ; CKD stage G5 cs-HR 2.81, 1.79 to 4.42 ) as compared to eGFR $>60 \mathrm{ml} / \mathrm{min}$. In the non-hip fracture cohort, HRs for fracture and mortality in the first and second year were comparable with the hip fracture cohort.

\section{Discussion}

In this study, CKD stages G3-G5 was not associated with the risk of subsequent major non-hip fragility fractures following a hip fracture compared to eGFR $>60 \mathrm{ml} / \mathrm{min}$. However, CKD stages G3-G5 was associated with a lower risk of subsequent any non-hip fracture and increased risk of all-cause mortality. Risk of all-cause mortality was 1.5- to 3-fold higher in patients with CKD G4 and G5 as compared to eGFR > $60 \mathrm{ml} / \mathrm{min}$. In the non-hip fracture cohort, there was no increased risk of major non-hip fragility fractures in CKD G3G5 compared to eGFR $>60 \mathrm{ml} / \mathrm{min}$, but the mortality risk was increased in CKD G3-G5.

One of the strengths of this study is that it is a large, population-based cohort, which is representative for the UK population. While patients with CKD, especially stages G4 G5, have regular check-ups with nephrologists, it was demonstrated by Jameson et al. that the prevalence of CKD stages G3-G5 in 2010 in the CPRD was consistent with the prevalence found in other large cross-sectional studies and a national survey [21]. Furthermore, in this CPRD cohort, longitudinal data was available for risk factors allowing adjustment for several confounders including comorbidities, falling, risk factors for osteoporosis, use of drugs and lifestyle factors. Our study has several limitations. First, in this study, only community-dwelling patients were included. In 2014, Gibson-Smith et al. demonstrated in a hip fracture cohort from CPRD that $10 \%$ of the patients were transferred out of the database after hip fracture. A possible reason for this was that patients were transferred to nursing homes [22]. The mortality risk might be higher in the nursing home population than in the community-dwelling population. But this study provides no evidence on this population. Another limitation was that we were not able to study subsequent hip fracture due to the coding practices in UK primary care (it is difficult to differentiate between repeat recording of a previous fracture and new recording of an incident fracture). Further, our data source contains insufficient information to adequately identify CKD stages according to the KDOQI or KDIGO guidance with a CGA classification, based on cause, GFR category and albuminuria category. Since we did not have data on proteinuria and cause, we were not able to differentiate between CKD stage G1, stage G2 and no CKD in the eGFR category of $>60 \mathrm{ml} / \mathrm{min}$.

This is the first study that evaluated subsequent fracture risk after hip fracture in patients with CKD. Previous studies focused on the association between CKD and the risk of a first fragility fracture. The studies of Nickolas et al., Dukas et al., Alem et al., Chen et al. and Dooley et al. showed an increased risk with worsening kidney function [2-6]. In contrast to these studies, we found no association of CKD with subsequent major non-hip fragility fracture risk after a hip fracture and the risk of any subsequent non-hip fracture was even lower in CKD stages G3-G5 compared to eGFR > $60 \mathrm{ml} / \mathrm{min}$. This difference might be attributable to the higher mortality rate in CKD patients who sustained a hip fracture. Further, Nickolas et al. and Dukas et al. both performed a crosssectional study [2, 3], whereas our study was a retrospective cohort study. The longer follow-up in three of the studies also might contribute to the different results [4-6]. Alem et al. performed the study in a dialysis population. The dialysis population has a higher fracture risk than $\mathrm{CKD}$ stages $\mathrm{G} 3$ and G4. We did exclude dialysis patients and that might explain the higher fracture risk in the study of Alem et al. [4]. However, one Canadian population-based cohort study of 1.8 million participants aged $>18$ years did not find an association of increased fracture rates (hip, vertebrae and wrist) with an eGFR $<60 \mathrm{ml} / \mathrm{min}$, independent of age and sex. The median follow-up was 4.4 years, median age was 47 years and $7.1 \%$ had an eGFR $<60 \mathrm{ml} / \mathrm{min}$ [23]. These results are in line with our result of no increased fracture risk in CKD G3-G5 compared to eGFR $>60 \mathrm{ml} / \mathrm{min}$. The main differences of the studies are the median age, median follow-up and the outcome: fragility fractures in the Canadian cohort and subsequent fractures in our hip fracture cohort.

Our results of a 1.5- and 3-fold increased risk of mortality with CKD stages G4 and G5 after hip fracture are in line with the results of Nitsch et al. [24], although Nitsch et al. studied the hip fracture-related mortality instead of all-cause mortality post-hip fracture as we did in our analyses. Nitsch et al. showed in a population of 13,167 UK patients (median age of 80.3 years (IQR 77.2-84.1), 61\% women, median followup 7.25 years (IQR 3.79-8.77)) a doubled risk of hip fracturerelated mortality with an eGFR $<45 \mathrm{ml} / \mathrm{min}$ [24]. Our results are not fully in line with the results of Robertson et al. [25], who showed an increased post-hip fracture mortality risk (allcause mortality post-hip fracture and hip fracture-related mortality post-hip fracture) for patients with CKD stage G4 but not for patients with CKD stages G3a, G3b, G5, G3-G5. However, in that study, patients aged 15 and older were included, and the mean age of the CKD stages G3-G5 population was lower than in our study (74.8 vs. 84 years) [25]. The lower mean age in the population of Robertson et al. might explain the differences in mortality risk. In our control patients, the mortality risk was increased in the same range as in the post-hip fracture patients in stages G3-G5, G4 and G5. CKD has been associated with an increased risk of mortality and cardiovascular mortality which may explain our results of an increased mortality risk in both the hip fracture and control cohort [26, 27]. 
An unexpected finding in this study was that CKD after hip fracture was not associated with subsequent non-hip (fragility) fracture. A competing risk of all-cause mortality may be a sensible explanation for these observations. Over the past years, there has been more awareness of competing risks in research including elderly [28, 29]. Not accounting for competing risks may result in overestimated incidence rates and HRs. Competing risks are mainly relevant when the follow-up period is longer than 5 years, or when the competing event occurs equal or more often than the outcome of interest [30]. In the present study, 15,828 patients had died while only 1855 had suffered from a major non-hip fragility fracture after the index hip fracture. Surprisingly, we found no increased risk of a subsequent major non-hip fragility fracture with a worsening CKD stage. However, when we studied the cause-specific HR, we found an increased risk of mortality with a worsening CKD. We think that as a consequence of the high mortality rates in the group of patients with a worse kidney function, these patients were less susceptible to a new fracture. Due to the high mortality rates, the median exposure time was shorter, especially in the hip fracture cohort. This could then have resulted in the findings of the present study, showing no association between CKD stage and risk of subsequent fracture. We think that in the non-hip fracture group, the control cohort, the competing risk of fracture and death also might have resulted in the finding of no increased risk of major non-hip fragility fractures with worsening CKD stage. Presence of a competing risk of fracture and death in elderly with CKD has been reported previously [31,32].

Our results showed that the major non-hip fragility fracture IR in our hip fracture cohort was higher as compared to the IR of major non-hip fragility fracture in the non-hip fracture cohort, which is in line with previous research that showed that a previous fracture increased the risk of a subsequent fracture [7-10]. However, the IRs for mortality were in both cohorts about 10 times higher than the IRs for major non-hip fragility fracture, showing that with respect to the absolute risks, mortality occurs much more frequently and is potentially of more clinical importance in this case.

In conclusion, this study did not demonstrate an increased risk of subsequent major non-hip fragility fractures following a hip fracture in patients with CKD stages G3-G5 compared to eGFR $>60 \mathrm{ml} / \mathrm{min}$. In addition, there also was no association between major non-hip fragility fracture risk and renal function in the control population. However, mortality risk was substantially increased in both cohorts of hip fracture and non-hip fracture patients with CKD stages G4 and G5 as compared to eGFR $>60 \mathrm{ml} / \mathrm{min}$. The elevated mortality risk may (up to $>500$ per 1000 person years), as competing risk, explains our main finding that CKD stages G3-G5 should not be regarded as an important additional risk fracture for subsequent fractures in this population. Nevertheless, the absolute fracture risk in this population is still around 50 per 1000 person years. This emphasises the need of adequate management of renal failure especially since the options for anti-osteoporosis treatment in patients with eGFR $<30 \mathrm{ml} /$ min are limited.

\section{Compliance with ethical standards}

Conflict of interest Dr. Wyers, Dr. Souverein, Dr. van Staa and Dr. Driessen have nothing to disclose.

Dr. de Bruin reports personal fees from Pfizer, personal fees from Novartis, personal fees from Sanofi, outside the submitted work; Dr. van den Bergh reports grants and personal fees from Amgen, grants and personal fees from Eli Lilly, personal fees from UCB, outside the submitted work; Dr. Geusens reports grants and personal fees from Amgen, grants from Pfizer, grants from MSD, grants from UCB, grants from Abbott, grants and personal fees from Lilly, grants from BMS, grants from Novartis, grants from Roche, grants from Will Pharma, outside the submitted work; Dr. de Vries supervises various PhD students who are employed with F. Hoffmann la Roche Ltd. (Welwyn Garden City UK and Basel, Switzerland). The topics of their PhDs are not related to the current work. Dr. de Vries has not received any fees or reimbursements for this.

Ethical considerations Ethical approval by the institutional or national research ethics committee was not required.

For this type of study, formal consent is not required.

Open Access This article is licensed under a Creative Commons Attribution-NonCommercial 4.0 International License, which permits any non-commercial use, sharing, adaptation, distribution and reproduction in any medium or format, as long as you give appropriate credit to the original author(s) and the source, provide a link to the Creative Commons licence, and indicate if changes were made. The images or other third party material in this article are included in the article's Creative Commons licence, unless indicated otherwise in a credit line to the material. If material is not included in the article's Creative Commons licence and your intended use is not permitted by statutory regulation or exceeds the permitted use, you will need to obtain permission directly from the copyright holder. To view a copy of this licence, visit http://creativecommons.org/licenses/by-nc/4.0/.

\section{References}

1. Pimentel A, Ureña-Torres P, Zillikens MC, Bover J, Cohen-Solal M (2017) Fractures in patients with CKD-diagnosis, treatment, and prevention: a review by members of the European Calcified Tissue Society and the European Renal Association of Nephrology Dialysis and Transplantation. Kidney Int 92:13431355. https://doi.org/10.1016/j.kint.2017.07.021

2. Nickolas TL, McMahon DJ, Shane E (2006) Relationship between moderate to severe kidney disease and hip fracture in the United States. J Am Soc Nephrol 17:3223-3232. https://doi.org/10.1681/ ASN.2005111194

3. Dukas L, Schacht E, Stähelin HB (2005) In elderly men and women treated for osteoporosis a low creatinine clearance of $<65 \mathrm{ml} / \mathrm{min}$ is a risk factor for falls and fractures. Osteoporos Int 16:1683-1690. https://doi.org/10.1007/s00198-005-1903-7

4. Alem AM, Sherrard DJ, Gillen DL, Weiss NS, Beresford SA, Heckbert SR, Wong C, Stehman-Breen C (2000) Increased risk of 
hip fracture among patients with end-stage renal disease. Kidney Int 58:396-399. https://doi.org/10.1046/j.1523-1755.2000.00178.x

5. Dooley AC, Weiss NS, Kestenbaum B (2008) Increased risk of hip fracture among men with CKD. Am J Kidney Dis 51:38-44. https:// doi.org/10.1053/j.ajkd.2007.08.019

6. Chen H, Lips P, Vervloet MG, van Schoor N, de Jongh RT (2018) Association of renal function with bone mineral density and fracture risk in the Longitudinal Aging Study Amsterdam. Osteoporos Int 29:2129-2138. https://doi.org/10.1007/s00198-018-4592-8

7. Klotzbuecher CM, Ross PD, Landsman PB, Abbott TA 3rd, Berger M (2000) Patients with prior fractures have an increased risk of future fractures: a summary of the literature and statistical synthesis. J Bone Miner Res 15:721-739. https://doi.org/10.1359/jbmr.2000. 15.4.721

8. Center JR, Bliuc D, Nguyen TV, Eisman JA (2007) Risk of subsequent fracture after low-trauma fracture in men and women. JAMA 297:387-394. https://doi.org/10.1001/jama.297.4.387

9. Huntjens KMB, Kosar S, van Geel TACM, Geusens PP, Willems P, Kessels A, Winkens B, Brink P, van Helden S (2010) Risk of subsequent fracture and mortality within 5 years after a non-vertebral fracture. Osteoporos Int 21:2075-2082. https://doi.org/10.1007/ s00198-010-1178-5

10. van Helden S, Cals J, Kessels F, Brink P, Dinant GJ, Geusens P (2005) Risk of new clinical fractures within 2 years following a fracture. Osteoporos Int 17:348-354. https://doi.org/10.1007/ s00198-005-2026-x

11. Bliuc D, Tran T, Alarkawi D, Nguyen TV, Eisman JA, Center JR (2016) Secular changes in postfracture outcomes over 2 decades in Australia: a time-trend comparison of excess postfracture mortality in two birth controls over two decades. J Clin Endocrinol Metab 101:2475-2483. https://doi.org/10.1210/jc.2016-1514

12. Bliuc D, Alarkawi D, Nguyen TV, Eisman JA, Center JR (2015) Risk of subsequent fractures and mortality in elderly women and men with fragility fractures with and without osteoporotic bone density: the Dubbo osteoporosis epidemiology study. J Bone Miner Res 30:637-646. https://doi.org/10.1002/jbmr.2393

13. Herrett E, Gallagher AM, Bhaskaran K, Forbes H, Mathur R, van Staa T, Smeeth L (2015) Data resource profile: clinical practice research datalink (CPRD). Int J Epidemiol 44:827-836. https:// doi.org/10.1093/ije/dyv098

14. van Staa TP, Abenhaim L, Cooper C, Zhang B, Leufkens HG (2000) The use of a large pharmacoepidemiological database to study exposure to oral corticosteroids and risk of fractures: validation of study population and results. Pharmacoepidemiol Drug Saf 9:359-366. https://doi.org/10.1002/1099-1557(200009/10)9: 5<359::AID-PDS507>3.0.CO;2-E

15. Gallagher AM, Dedman D, Padmanabhan S et al (2019) The accuracy of date of death recording in the Clinical Practice Research Datalink GOLD database in England compared with the Office for National Statistics death registrations. Pharmacoepidemiol Drug Saf. https://doi.org/10.1002/pds.4747

16. Eppenga WL, Lalmohamed A, Geerts AF, Derijks HJ, Wensing M, Egberts A, de Smet PA, de Vries F (2014) Risk of lactic acidosis or elevated lactate concentrations in metformin users with renal impairment: a population-based cohort study. Diabetes Care 37:22182224. https://doi.org/10.2337/dc13-3023

17. Group GOKCW (2013) KDIGO 2012 clinical practice guideline for the evaluation and management of chronic kidney disease. Kidney Int Suppl 3:1-150

18. Jain P, Calvert M, Cockwell P, McManus RJ (2014) The need for improved identification and accurate classification of stages 3-5 chronic kidney disease in primary care: retrospective cohort study. PLoS One 9:e100831. https://doi.org/10.1371/journal.pone. 0100831
19. Kohl M, Plischke M, Leffondré K, Heinze G (2015) PSHREG: a SAS macro for proportional and nonproportional subdistribution hazards regression. Comput Methods Prog Biomed 118:218-233. https://doi.org/10.1016/j.cmpb.2014.11.009

20. Bliuc D, Nguyen TV, Eisman JA, Center JR (2014) The impact of nonhip nonvertebral fractures in elderly women and men. J Clin Endocrinol Metab 99:415-423. https://doi.org/10.1210/jc.2013-3461

21. Jameson K, Jick S, Hagberg KW, Ambegaonkar B, Giles A, O'Donoghue D (2014) Prevalence and management of chronic kidney disease in primary care patients in the UK. Int J Clin Pract 68: 1110-1121. https://doi.org/10.1111/ijcp.12454

22. Gibson-Smith D, Klop C, Elders PJM, Welsing PM, van Schoor N, Leufkens HG, Harvey NC, van Staa T, de Vries F (2014) The risk of major and any (non-hip) fragility fracture after hip fracture in the United Kingdom: 2000-2010. Osteoporos Int 25:2555-2563. https://doi.org/10.1007/s00198-014-2799-x

23. Elliott MJ, James MT, Quinn RR, Ravani P, Tonelli M, PalaciosDerflingher L, Tan Z, Manns BJ, Kline GA, Ronksley PE, Hemmelgarn BR (2013) Estimated GFR and fracture risk: a population-based study. Clin J Am Soc Nephrol 8:1367-1376. https://doi.org/10.2215/CJN.09130912

24. Nitsch D, Mylne A, Roderick PJ et al (2009) Chronic kidney disease and hip fracture-related mortality in older people in the UK. Nephrol Dial Transplant 24:1539-1544. https://doi.org/10.1093/ ndt/gfn678

25. Robertson L, Black C, Fluck N, Gordon S, Hollick R, Nguyen H, Prescott G, Marks A (2018) Hip fracture incidence and mortality in chronic kidney disease: the GLOMMS-II record linkage cohort study. BMJ Open 8:e020312. https://doi.org/10.1136/bmjopen2017-020312

26. Go AS, Chertow GM, Fan D, McCulloch C, Hsu CY (2004) Chronic kidney disease and the risks of death, cardiovascular events, and hospitalization. N Engl J Med 351:1296-1305. https://doi.org/10.1056/NEJMoa041031

27. Roderick PJ, Atkins RJ, Smeeth L, Mylne A, Nitsch DD, Hubbard RB, Bulpitt CJ, Fletcher AE (2009) CKD and mortality risk in older people: a community-based population study in the United Kingdom. Am J Kidney Dis 53:950-960. https://doi.org/10.1053/ j.ajkd.2008.12.036

28. Noordzij M, Leffondré K, van Stralen KJ et al (2013) When do we need competing risks methods for survival analysis in nephrology? Nephrol Dial Transplant 28:2670-2677. https:// doi.org/10.1093/ndt/gft355

29. Koller MT, Raatz H, Steyerberg EW, Wolbers M (2012) Competing risks and the clinical community: irrelevance or ignorance? Stat Med 31:1089-1097. https://doi.org/10.1002/sim.4384

30. Berry SD, Ngo L, Samelson EJ, Kiel DP (2010) Competing risk of death: an important consideration in studies of older adults. J Am Geriatr Soc 58:783-787. https://doi.org/10.1111/j.1532-5415.2010. 02767.x

31. Hall RK, Sloane R, Pieper C, van Houtven C, LaFleur J, Adler R, Colón-Emeric C (2018) Competing risks of fracture and death in older adults with chronic kidney disease. J Am Geriatr Soc 66:532538. https://doi.org/10.1111/jgs.15256

32. Pérez-Sáez MJ, Prieto-Alhambra D, Barrios C et al (2015) Increased hip fracture and mortality in chronic kidney disease individuals: the importance of competing risks. Bone 73:154-159. https://doi.org/10.1016/j.bone.2014.12.020

Publisher's note Springer Nature remains neutral with regard to jurisdictional claims in published maps and institutional affiliations. 